\title{
Study on Virtual Technology Application in Display and Exhibition Design
}

\author{
Zhang Zhi Min \\ Department of Tourism \\ Chengdu Polytechnic \\ Chengdu, China \\ zzm1127@163.com
}

\author{
Lai Bin \\ Department of Tourism \\ Chengdu Polytechnic \\ Chengdu, China \\ mbalaibin@163.com
}

\begin{abstract}
Display is one of the basic daily activities for human beings, and more and more attention has been paid to the clarity of display information. Under the guidance of information era, virtual imitation system can show the actual image and the application of virtual technology in teaching of design major [1] has broken through restriction factors of practical teaching. It can help teachers and students complete the task of project design. Nowadays, this technique becomes quite popular with the extensive teachers and students as an effective means of education. In this paper, the use conditions of virtual technology are discussed.
\end{abstract}

Keywords—Display and Exhibition Design; Virtual Technology; Application; Study

\section{INTRODUCTION}

Virtual reality (VR) was proposed by the founder of VPL Company, J. Lanier. This technique is applied in virtue of computer system[2]. It is able to create a vivid threedimensional virtual reality environment. In this way, audiences can not only see lively three-dimensional scenes but also hear stereo sounds. The application of this technique in Display and Exhibition Design has made up the defects of traditional teaching, and researches are conducted for it. Generally speaking, virtual technology optimizes the teaching effect through three-dimensional software, interactive design and simplified design procedure.

\section{EXHIBITION BOOTH CONSTRUCTION VIA THREE- DIMENSIONAL DESIGN TECHNOLOGY}

At present, 3D-MAX, Rhino and MAYA are all frequently-used modeling software, and the use of virtual reality technology in Display and Exhibition Design has already been popularized. In the following, the author will conduct an in-depth analysis on the application of virtual technology by taking design of the electronic product project, currency-counting machine as an example.

Firstly, three-dimensional model establishment for the currency-counting machine is completed under the introduction and application of three-dimensional design software. At the current stage, the three-dimensional design software used by teachers the most frequently in teaching of design major is 3DS-Max software developed by Autodesk. As for the reason why this software enjoys great popularity and is used frequently, it can complete the three-dimensional modeling content within a very short time, and the quality can be guaranteed. In addition, owing to the application of threedimensional software design technology in exhibition booth or exhibition hall process, quality problems of materials are handled more scientifically and properly. Moreover, some images can be pasted to the surface layer of the design product smoothly and efficiently. Of course, the new technology of three-dimensional design also shows a good effect in spatial deformation.

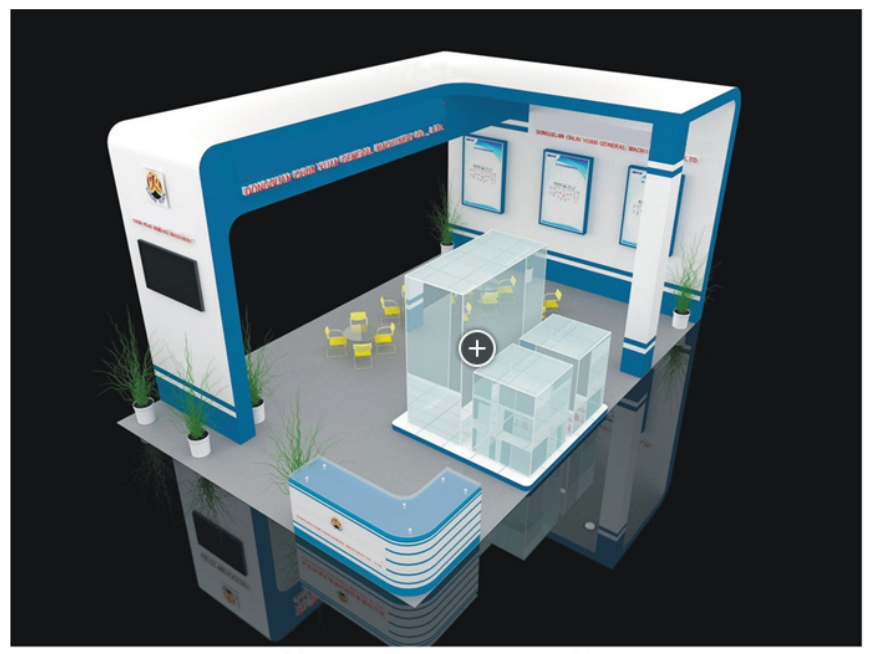

Fig. 1. The Space-unit

III. EXPLORATION on the process of currency-counting machine exposition or exhiBITION BOOTH CONSTRUCTION

After presentation model of the electronic product currency-counting machine is established and perfected, the next step is to select the virtual exhibition and display platform. In design teaching, author of this paper suggests that teachers should adopt Cult3D software developed by Cycore. For the construction of currency-counting machine exposition or exhibition booth, the specific structure should be grasped first, and the project of pedestal construction must be completed. Then internal setting of three-dimensional exhibition booth pedestal for currency-counting machine should be completed via virtual design technology. The major contents include the following aspects: laser emission instrument is installed inside 


\section{B ATLANTIS PRESS}

the pedestal; spherical glass cover is installed above the pedestal, and it is opposite against the laser emission instrument; three-dimensional display is installed inside the glass cover. The three-dimensional exhibition booth of currency-counting machine is analyzed. As for the particularity of its pedestal, a circular orbit is set and a device related to transmission is installed below it. Besides, 6 regions are designed for the so-called circular orbit, and an imaging lens is installed in the central position of every region. This imaging lens is connected to a miniature camera. Under the assistance of DLP processor, the author has smoothly designed a complete three-dimensional exhibition booth of currencycounting machine without dead angles in all directions that can comprehensively project the internal product structure of currency-counting machine. In a word, the application of virtual technology in Display and Exhibition Design of electronic products requires the support of a virtual exhibition booth or exhibition hall as well as the cooperation of Cult3D software. Convenience and simplicity of this software perfectly match the software and hardware research and development environment of design major teaching. It has realized the application target of virtual technology by implementing the working content of virtual interactive design.

The design achievements of currency-counting machine products are often issued via browsers. Of course, this step is based on complete design drawings. The plane quantity of model established via 3ds-Max software should not be too huge, so as to ensure the accuracy of currency-counting machine design model. Establishment of currency-counting machine model should strictly follow various structures in Cult3D software. After any format (jpeg or gif) is output, size and capacity of the file are controlled (as shown in Fig. 2);

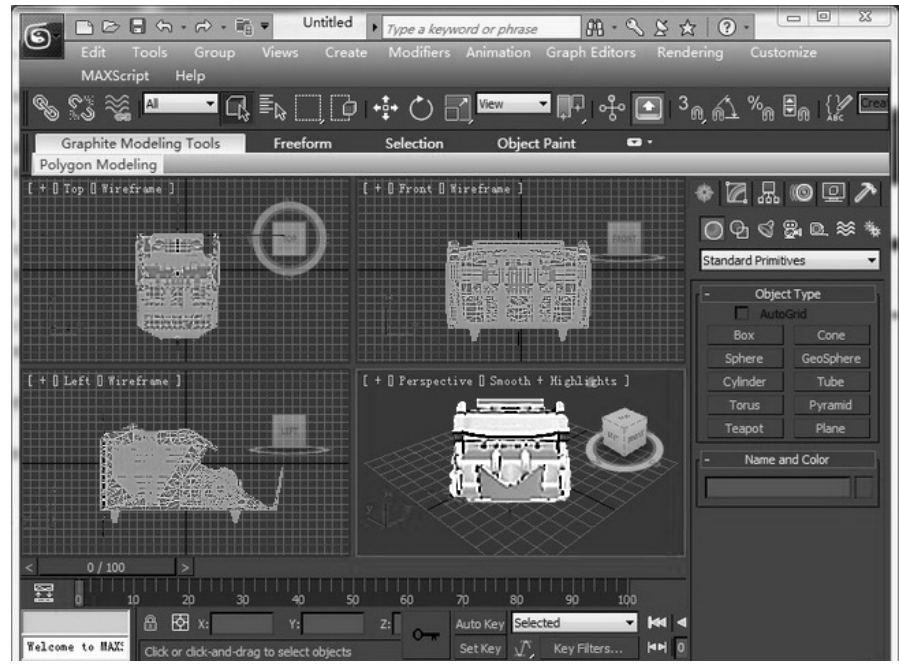

Fig. 2. 3D-MAX interface processing

Next, it comes to the installation of Cult3D Exporter for 3dsMax plugin. Construction of the object group should be completed, and Cult3D Designer procedure needs to be initiated. The input command should be imported smoothly and orderly. In addition, the special material in C3D file can design many combination forms. After the working task of interactive design is completed via virtual technology, by clicking the "save" button, this software can be compiled on relevant interfaces and arrangement of trigger events can be realized. At this time, people can know about the currency-counting machine product developed via virtual technology by means of the browser. Owing to the participation of Photoshop, the products designed will bring about more abundant aesthetic feelings to audiences.

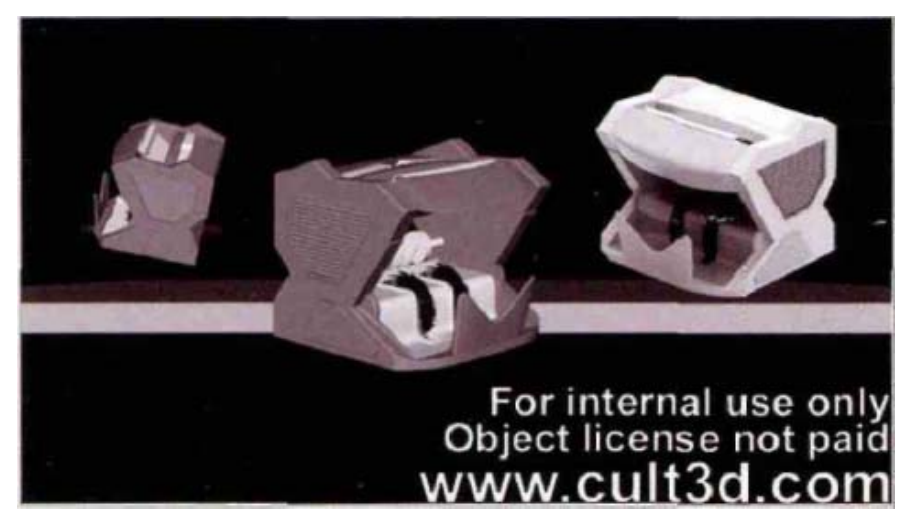

Fig. 3. Virtual display in the webpage

IV. APPLICATION OF 3DS MAX VIRTUAL REALITY TECHNOLOGY IN JEWELRY EXPOSITION OR EXHIBITION BOOTH DESIGN

Firstly, a three-dimensional virtual model is established via $3 \mathrm{dx}$ Max. In this process, diversified modeling should be conducted for different structures and styles of different virtual models. The transformation of materials can be realized in Cult3D [3]. Mapping is comparatively complex. It not only requires the strong support of virtual technology but also needs the cooperation of Cult3D software with GIF or JPEG formats. The target of file size control should be realized, and the system pressure needs to be reduced.

In order to complete the working task of exposition or exhibition booth design, 3ds Max virtual reality technology can be adopted with the help of programming method. The program of "VRML JAVA3D OpenGL" can be used to write statements and then complete construction of threedimensional model [4]. Actually, owing to the application of $3 \mathrm{dx}$ Max three-dimensional design software introduced by Autodesk, effective management and control can be realized for excellent texture mapping in the process of jewelry exposition or exhibition booth construction. Moreover, establishment of excellent models can be completed within a short time. Of course, it can also be used to solve various spatial warping and deformation problems deriving from the process of exposition or exhibition booth design and construction[5]. In fact, the application of 3ds Max in the process of exposition or exhibition booth design is mainly completed under the help of file delivery formats like WRL, C3D, ASE and OBJ. Of course, due to the interactivity and expansibility possessed by JAVA language of Cult3D, the exposition or exhibition booth model can be smoothly embedded into HTML page or other program systems[6].

The application of virtual reality technology in the process of modern space exposition or exhibition booth construction 
has changed human life and working styles as well as consumption concepts to a great degree. With the popularization and application of internet technology, exhibition industry becomes increasingly mature[7]. For instance, in 2010, China showed the three-dimensional garden form of World Expo on the internet platform for the first time, providing an immersive feeling for audiences.

\section{CONCLUSIONS}

In conclusion, virtual technology is extensively applied to modern design, and has obtained extremely impressive effects. For teaching of Display and Exhibition Design, the application of this technology has created a virtual experiment environment with stereoscopic and real feelings. As a kind of reform and innovation for the traditional design teaching idea, it has adjusted and optimized the teaching environment and emancipated the teaching thought. Hence, design major is bound to practice virtual route in the future, so as to improve teaching efficiency and complete the great target of cultivating high-quality talents!

\section{REFERENCES}

[1] ZHAO Qinghua. Study on Application of Virtual Technology in Convention and Exhibition Art Design [J]. Art Education, 2015, 02: 7172 .

[2] SHENG Xia and PAN Qian. Application of Virtual Display Technology in Modern Display Design Teaching [J]. Journal of Suzhou University, 2015, 03: 124-127.

[3] YANG Xiaoliang. Study on Application of Virtual Reality Technology in New Media Display Design [J]. Art Education, 2015, 08: 54-57.

[4] HUANG Wenqing. A Simple Analysis on Application of Interactive Technology in Digital Media Art [J]. Vocational Technology, 2012, 02: 128-129.

[5] SHEN Qiu. Thinking about Showcase Modern Museum Display [J]. Popular Science \& Technology, 2013, 01: 98-100.

[6] SHAN Jixiang. Explanation on Ideological Value and Ornamental Value of Museum Display and Exhibition [J]. Relics from South, 2013, 03: 1-8.

[7] CAI Xiuzhen. Analysis on Virtual Reality Technology in Dynamic Display [J]. Journal of Shandong Agricultural Administrators' College, 2016, 02: 149-150. 